\title{
Nationale Rechtsinstitute als Bausteine europäischen Verwaltungsrechts
}

\author{
Rezeption und Wandel zwischen Konvergenz und Wettbewerb der \\ Rechtsordnungen
}

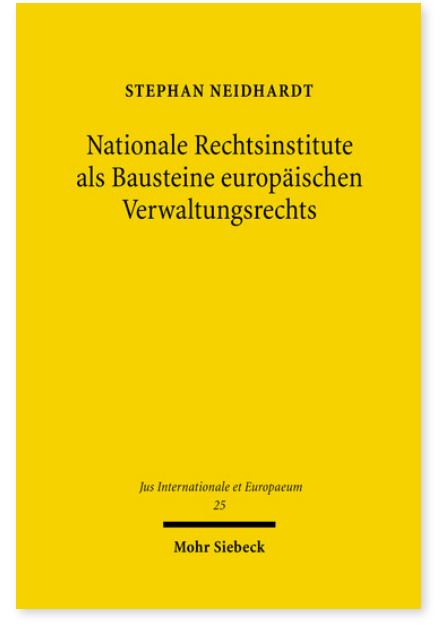

2008. XXII, 273 Seiten. JusIntEu 25

ISBN 978-3-16-151164-6

DOI 10.1628/978-3-16-151164-6

eBook PDF 79,00€

ISBN 978-3-16-149860-2

fadengeheftete Broschur 79,00€
Das Gemeinschaftsrecht und die mitgliedstaatlichen Verwaltungsrechtsordnungen sind seit Beginn der europäischen Integration durch einen andauernden Prozeß wechselseitiger Rezeption von Rechtsinstituten aufeinander angewiesen. Diese Rechtsinstitute stellen insofern zentrale Bausteine des europäischen Verwaltungsrechts dar. Um die komplexen

Rezeptionsprozesse zwischen Gemeinschaftsrecht und mitgliedstaatlichen Rechtsmassen genauer abbilden und bewerten zu können, erweist sich ein methodischer Ansatz als sinnvoll, der über die traditionellen Disziplinengrenzen zwischen nationaler Rechtsdogmatik und Rechtsvergleichung hinausreicht. Mithilfe der von Stephan Neidhardt erprobten »dynamischen« Rechtsvergleichung lassen sich in der Tat genauere Aussagen zum Problemfeld der Europäisierung nationalen Verwaltungsrechts gewinnen. Der Autor untersucht Rezeption und Wandel des deutschen Vertrauensschutzes sowie des französischen intérêt pour agir auf ihrem Weg von der Entstehung in einer nationalen »Ursprungsrechtsordnung über das Gemeinschaftsrecht bis zur Einwirkung auf eine andere mitgliedstaatliche »Empfangsrechtsordnung«. Daraufhin arbeitet er Kriterien heraus, die die Entscheidung für oder gegen eine Übernahme gemeinschaftsrechtlicher Vorgaben auch für den nicht europäisierten Bereich des nationalen Rechts determinieren. Vor diesem Hintergrund thematisiert er die praktische Umsetzbarkeit eines Wettbewerbs der Verwaltungsrechtsordnungen durch »Benchmarking« als Mittel zur schonenderen Einpassung europäischer Vorgaben in das nationale Verwaltungsrecht.

Das Werk wurde mit dem »Carl-von-Rotteck-Preis« 2008 der Universität Freiburg und dem »Rhodia-AcetowNachwuchsförderpreis« 2008 des Frankreich-Zentrums der Universität Freiburg ausgezeichnet.

Stephan Neidhardt Geboren 1977; Studium des deutschen, französischen und Europarechts in Köln (LL.M.), Paris (Maîtrise en droit) und Freiburg i.Br.; 2008 Promotion; Rechtsreferendar in Berlin.

Jetzt bestellen:

https://mohrsiebeck.com/buch/nationale-rechtsinstitute-als-bausteine-europaeischen-verwaltungsrechts-9783161511646? no_cache $=1$

order@mohrsiebeck.com

Telefon: $+49(0) 7071-923-17$

Telefax: $+49(0) 7071-51104$ 